NEW LITERARIA-

An International Journal of Interdisciplinary Studies in Humanities

Volume 3, No. 1, January-February, 2022, PP. 37-52

ISSN: 2582-7375

DOI: https://dx.doi.org/10.48189/nl.2022.v03i1.005

www.newliteraria.com

\title{
The Future of Cultural Studies and the Humanities
}

\section{Amalia Călinescu}

\begin{abstract}
The current paper discusses the computerised future of cultural studies and the humanities by analysing the relation between theory and practice and the complementarity of science and literature. As a case study, the paper reports briefly on the research project Distorted Temporality in Kazuo Ishiguro's Novels: A Holistic Approach, which proposes a theoretical and practical approach to the distorted nature of time in Ishigurian characters' perception. The theoretical and empirical objectives of the study consisted in helping Ishiguro's readers understand their natural tendency to distort time. The hypotheses and sub-hypotheses were tested using a quantitative approach, through a self-administered questionnaire in English, with closed- and open-ended questions. One set of data was collected from 2610 Romanian and foreign respondents, with regard to their perception of time and their interpretation of Kazuo Ishiguro's novels. The data set was then analysed using descriptive, inferential, and pathanalysis methods (frequencies, percentages, PLS-PM, t-tests, ANOVA, multiple linear and binary logistic regression, mediation, moderation, and moderated mediation) and two statistical programs (R studio 4.3.4. and WarpPLS 6.0.). The results indicate that, when embraced with an open heart, time distortion becomes a valuable tool for preserving human sanity and orientating human choices, decisions and actions in the right direction. Thus, if combined with the traditional approaches to literature, digital humanities and computational criticism could provide a more accurate image of world literature, far beyond the models of interpretation based on the literary canons.
\end{abstract}

Keywords: Kazuo Ishiguro, Interdisciplinarity, Digital Humanities, Computational Criticism, Psychotherapeutic Literature.

\section{Introduction}

Most academic disciplines and fields of research seek to understand human nature and the environment of its manifestation, yet only their cooperation can lead to sustainable development and progress for the wellbeing of the entire planet. Extrapolating what modern economist Eric D. Beinhocker says when referring to economies, one can state that, at the core of any concept, principle and law, there must be a holistic theory of human behaviour. Societies are ultimately made up of individuals (Beinhocker, 2006, p. 115).

According to Menand, literature can't be read literally. While "in non-literary texts rhetorical devices and figures of speech are incidental to the meaning, $[\ldots]$ in literary texts that sort of language - metaphors, symbols, allegories, all the forms and styles of fiction - are sources of meaning" (Menand, 2014, para. 57). Special aptitudes, either naturally or consciously acquired, are therefore used to analyse the logical affinities between concepts and ideas, which invariably leads to an integrated interpretation of texts, regardless of their original source. Although literary theory went into a decline when one of the most reputed critics, Paul de Man, was posthumously discovered to have lived a bigamous and pro-Nazi life (Menand, 2014), the usage of scientific disciplines to understand literature could revive the traditional 
way of reading fiction.

\section{Interdisciplinarity and Holism}

The concept of reality-within-reality could be regarded as the healthiest representation of specialisation and divisibility in accordance with the timeless relation between microcosm and macrocosm. The human being should invariably think holistically in order to understand beyond cognition its connection with the whole Universe and thus recognise universal truths as the common denominators of all forms of human manifestation, past, present and future.

Lovejoy openly supports the integration of all fields of specialisation - that is, the alliance of all studies and manifestations of the human mind (Lovejoy, 1940, pp. 2-3). Disciplines may be indeed divided for pragmatic reasons, yet the comprehension process has been and will always remain a unitary whole. The discrepancy between procedure and subject has produced serious gaps in the study of human history, not to mention significant errors and distortions. Indispensable though it may be for human progress, specialisation cannot be a sufficient reality, so scholars and researchers who frequently use other fields of knowledge to understand their own areas of interest should be overtly encouraged and supported (Lovejoy, 1940, pp. 8-10). As such, the boundaries of the academic fields should become more and more flexible. Understanding a single literary passage could thus send both teachers and students to other fields of research, so accepting the liberalisation of academic boundaries could lead to a holistic interpretation of socio-economic, cultural and historical processes as well as everyday circumstances.

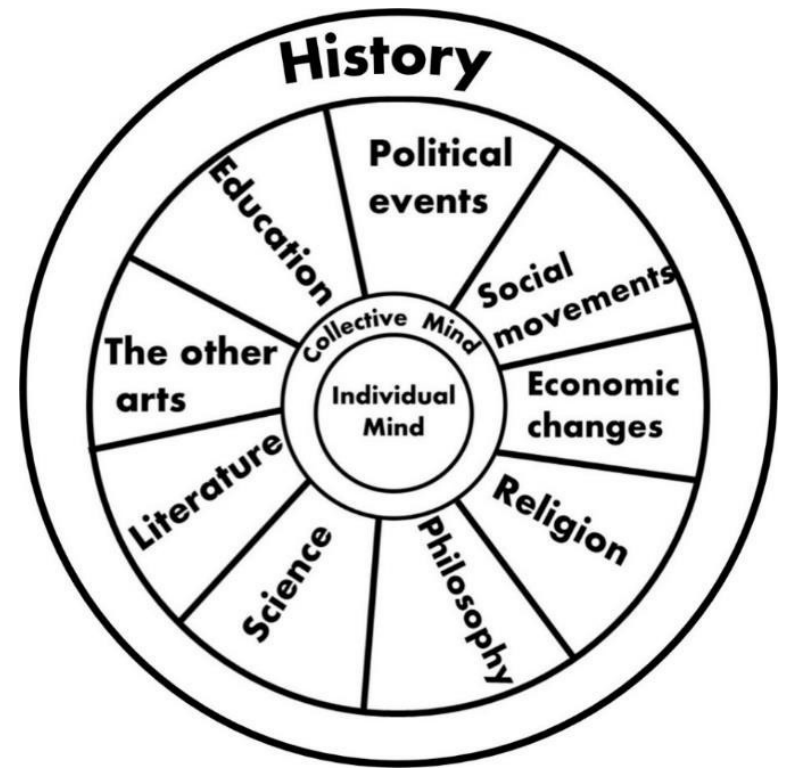

Figure 1: Lovejoy's integrative vision

The concept of mastermind alliance has been used consciously or otherwise since the beginning of human history. A popular example is Henry Ford, who managed to gather together many enlightened minds from various fields of expertise to put into practice his grand vision: a cheap car accessible to everyone (Hill, 2005, p. 37). In a similar vein, the fusion of elements has always existed under the name of influences (Lovejoy, 1940, p. 7):

- the influence of the classic on the modern

- the influence of European traditions and writings on American literature, arts, philosophy and social movements

- the influence of philosophical ideas on literature, arts, religion, social realities, morality, theories and educational methods

- the influence of scientific discoveries and theories on the cultural effects of applied science

- the evolution of the human motivation theories 
- metaphysical and historical determinism and neo-determinism

- individualism and collectivism

Human nature can be considered the binder of all existential episodes, offering critical analyses on genesis, development, dispersion, connectivity and the effects of ideas promoted peacefully, conflictingly or sacrificially. Whether it is regarded as an independent entity or as an instrumental reality for other studies, human nature can render the human script endless. As a result, by offering aesthetic joy beyond cognitive and utilitarian experience, any work of art establishes several types of relationships, with different actors: the creator, the reader, the listener and the viewer. But can external information truly enhance the reader's personal vision? C. S. Lewis has argued that the study of literary history inevitably leads to the accumulation of collateral information, which hinders the aesthetic experience. Literary works should therefore not be regarded as artistic manifestations of the personality of their creators, just as biography should not play such an important role in literary studies. In other words, aesthetic joy should be independent of the author's representation as a human being, character and personality; furthermore, it should remain unaffected by his experience, education or reputation (Lovejoy, 1940, p. 10). Yet it is hard to believe that the sources of aesthetic joy consist only in direct, uncontaminated contact with the literary text. One cannot completely ignore the psychological matrix of the reader as well as the writer's. The external stimulus that gives rise to the aesthetic experience may consist in the literary words, but the ability of the words to create emotional images and to convey ideas is due, in essence, to the associations created in the mind of the reader, and, implicitly, to his or her cultural experience. The function of psychotherapeutic imagination is therefore to revitalise the initial frames of reference and enhance the reader's aesthetic experience. Nevertheless, the idea that an author's private life can enhance the quality of his works remains a purely psychological reality. Any extrinsic information can contribute to the aesthetic experience generated by reading a literary text. Such knowledge can add a dramatic dimensionto a work of art, as a passage may be beautiful in itself, but its true value can only be perceived in the microcosmic entirety of the text itself.

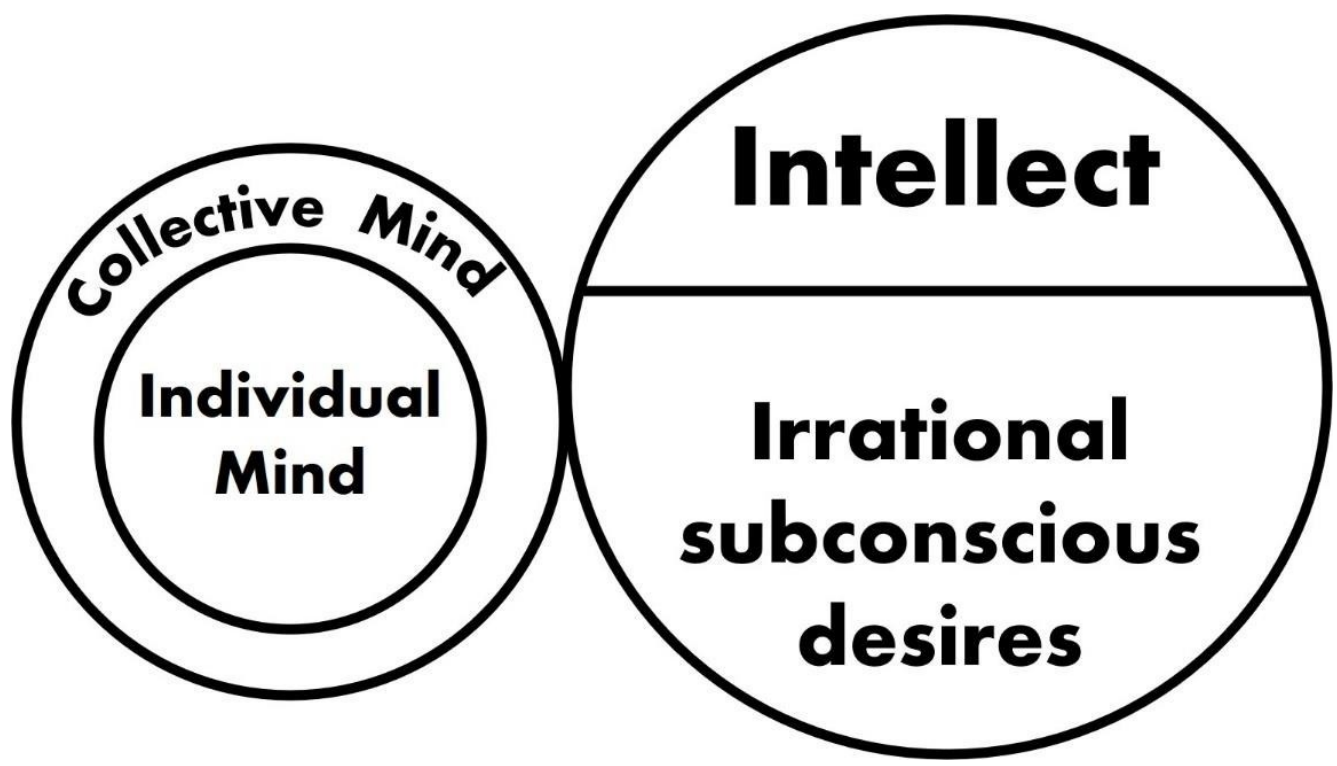

Figure 2: Lovejoy's mind vision

The complexity of human perception thus indicates that the intellect represents more than the logical determination of opinions and the historical circulation of thoughts. At the base of the individual and collective cognition lie both intellectual processes and irrational subconscious desires (Lovejoy, 1940, p. 20). Accepting the importance of the irrational in the healthy configuration of life, with its implications for every area of human thought, can only lead to the honest glorification of the continuous relationship between intuition and reason. As such, neither academics nor intellectual historiographers can be concerned with the history of the 
intellect alone, although they should still support the hypothesis that logic is an important (but not the most important) factor in the history of ideas. They should, however, also remain aware that each period tends to exaggerate the value of its own discoveries and rediscoveries. Radicalintellectualism of a certain period is naturally followed by an anti-intellectualist movement, because, according to the sociology of knowledge, collective thinking very much depends on all types of societal groups: social classes, generations, families, sects, schools (Lovejoy, 1940 , p. 18). Also considering an intuitive approach to all fields of research will help scientists, researchers and scholars to find integrated answers to the phenomena studied both separately and collectively and express them in accessible words so that the whole human world will benefit from them first-hand (Thompson, et al., 2011, p. 110).

\section{Theory and Experience}

Being unable to find a proper meaning for something that cannot be defined, nor can it be understood, does not mean that the undefinable phenomenon does not exist. It is practically a contradiction in terms to believe that one can fully understand something that goes far beyond the boundaries of the human mind. According to Osho, life and existence can neither be understood nor defined - they can only be experienced:

[...] it is the real which can make your life a joy, a bliss. The word "God" is not God, the word "love" is not love either. The poor people who go on thinking about the word "God" or the word "love" are simply missing a great opportunity. They may have known what God is, they may have become acquainted with the mysteries of love, but the word $[\ldots]$ is covering their eyes. The eyes of all knowledgeable people are so covered with theories, theologies, dogmas, creeds, that they cannot see. [...] And wisdom is $[. .$.$] a vision unclouded by all thoughts, unclouded by all dust. [...] Each$ moment we have to clean the dust. [...] Then we are simply a mirror, [...] mirroring all that is, within and without. Out of that mirroring, wisdom is born. $(2012$, p. 52)

Osho speaks concisely about the difference between theory and practice, considering the latter the very wisdom of life. In proving his point, the mystic gives the most significant examples for the human world: the concepts and realities of God and love. Speaking about God, however beautifully, does not equal the reality of experiencing God. Likewise, speaking about love cannot replace the experience of true love. According to Nietzsche, truth is " [...] a sum of human relations which have been poetically and rhetorically intensified, transferred, and embellished, and which, after long usage, seem to a people to be fixed, canonical, and binding. Truths are illusions which we have forgotten are illusions - they are metaphors that have become worn out and have been drained of sensuous force" (2006, p. 117). In Jung's view, the only reality is the individual. "The further we move away from the individual towards abstract ideas about homo sapiens, the more likely we are to fall into error" $(2012$, p. 45). The psychologist thus acknowledges the illusory power of provable knowledge: "It is a common illusion to believe that what we know today is all we ever can know. Nothingis more vulnerable than scientific theory, which is an ephemeral attempt to explain facts and not an everlasting truth in itself" (Jung, 2012, p. 234).

All knowledgeable humans - that is, people with many degrees for which they have learned a lot in higher educational institutions, like colleges and universities - are prone to knowing too much, and they can thus speak a lot about truths such as God and love. But the more they speak about such concepts, the farther they get from the experiences that have led to these concepts in the first place - so much so that, at some point, they can no longer make a difference between theory and practice, between knowing and doing. Osho states that human wisdom cannot have a universal quality unless it stems from practice, since speaking about something one has never experienced, however skilfully done, is just an illusion of true wisdom. Therefore, humans can remain ignorant, regardless of their culture and knowledge, unless they declutter their minds of useless descriptive and conceptual thoughts and start living intensely, without theorizing every single aspect before experiencing it (2012, p. 52). Although, 
according to Osho, all scholars are dependent on conceptualizing everything due to their impressive knowledge and intellect, they can also differentiate faster than others between theory and practice, and therefore they can consciously choose when to do and when to speak about doing for their own enlightenment. On the other hand, Osho's argument could prompt humankind to accept what it does not understand and to encourage collaboration of all fields for further deciphering the fabric of the Universe.

Everything is binary in the Universe, so any reality should be denoted by a specific conceptual instrument in order to create and preserve human communication and socialisation. The knowledge argument called Mary's room, proposed by philosopher Frank Jackson as a thought experiment, comes to emphasise Osho's spiritual argument that only experience can fulfil human's life (1982, pp. 127-136). Contrary to physicalism, Jackson believes that there is more to the Universe that meets the eye and therefore only through direct contact or experience can knowledge be obtained in order to complete the mental construct acquired through study (1986, pp. 291-295). In his thought experiment, Jackson allowed scientist Mary to accumulate all the information possible about colour while experiencing the world only in white and black:

Mary is a brilliant scientist who is, for whatever reason, forced to investigate the world from a black and white room via a black and white television monitor. She specializes in the neurophysiology of vision and acquires, let us suppose, all the physical information there is to obtain about what goes on when we see ripe tomatoes, or the sky, and use terms like "red", "blue", and so on. She discovers, for example, just which wavelength combinations from the sky stimulate the retina, and exactly how this produces via the central nervous system the contraction of the vocal cords and expulsion of air from the lungs that results in the uttering of the sentence "The sky is blue". [...] What will happen when Mary is released from her black and white room or is given a colour television monitor? Will she learn anything or not? (Jackson, 1982, p. 130)

Jackson's conclusion is that only by experiencing her knowledge of colour, a process called quale ${ }^{1}$, will Mary taste the true meaning of life, both as a human being and as an accomplished theorist.

\section{Literature and Science}

Science verifies and makes objective observations in order to create theories of the mind with predictive or explanatory value. Many scholars are still undecided whether literary criticism should be regarded as an art or as a science or both. "If you're an English major, what should you study: the idiosyncratic group of writers who happen to interest you (art), or literary history and theory (science)? If you're an English professor, how should you spend your time: producing 'readings' of the literary works that you care about (art), or looking for the patterns that shape whole literary forms or periods (science)" (Rothman, 2014, para. 1)?

In 2004, during a lecture at Case Western Reserve University, Kurt Vonnegut admitted that he had "tried to bring scientific thinking to literary criticism, and there [had] been very little gratitude for this" (Vonnegut, 2004, 00:32-00:38). Since the American writer continued to apply scientific thinking to literary criticism, especially in relation to the diagrammed story shapes he had created, in recent years, his studies have considerably grown in popularity. The worldwide acknowledgment of his interdisciplinary inventiveness, consisting in analysing humanistic works from both literary and scientific perspectives, can only prove that putting literature and science together may not be as farfetched as it sounds. Although Vonnegut's interdisciplinary attempt to marry sciences to the humanities in solving one of the greatest anthropological puzzles was first met with incredulity and even rejection, over time it has made greater sense of the decision-making process underlying human behaviour (Johnson, 2019). As such, in 2016, Vonnegut's eight story shapes from his Master's thesis in anthropology, which

\footnotetext{
${ }^{1}$ A Latin term: quale(sing.) - qualia (pl.)
} 
the University of Chicago had rejected, were put to test by a group of scientists from the Universities of Vermont and Adelaide. According to the author himself "there is no reason why the simple shapes of stories can't be fed into computers. They are beautiful shapes" (Hanschell, 2021). By mapping a corpus of literature of 1,737 English-language works of fiction from Project Gutenberg, researchers decided upon six recurring story shapes: (1) Rags to Riches (rising); (2) Riches to Rags (falling); (3) Man in a Hole (falling -> rising); (4) Icarus (rising -> falling); (5) Cinderella; Boy meets Girl (rising -> falling -> rising); (6) Oedipus (falling -> rising $->$ falling). Their findings indicate that the stories with a Rags-to-Riches trajectory are most prevalent, because people are conditioned to hope and believe that it will all turn out good in the end (Lafrance, 2016). "Somebody gets into trouble, gets out of it again. People love that story. They never get sick of it" (Vonnegut, 2004, 02:11-02:38; Gallo, 2014). However, the discrepancy between writers' predilection to the Rags-to-Riches scenario and readers' preferences for Oedipus, Man in Hole and Cinderella, based on the number of book downloads, indicate that modern people resonate more with the writers who dare to depict life as it is (Lafrance, 2016). The conclusion would be that all humans should embrace their lack of agency with grace and dignity: "This rise and fall is, in fact, artificial. It pretends that we know more about life than we really do" (Johnson, 2019, para. 8).

Another collaboration between literature and science comes from the study that analysed the spooky language of Macbeth, whose name is often avoided due to the many accidents and fatalities related to staging it (Thompson, 2021). The Scottish Tragedy is indeed about black magic and witches while it depicts bloody ghosts and moving woods and yet "its freaky qualities are deeper than just the plot devices and characters. [...] There's something subconsciously off about the sound of the play [...]. It's as if Shakespeare somehow wove a tiny bit of creepiness into every single line" (Thompson, 2021). After studying the language of the witches and the repetition of idioms such as "lost and won", Hope and Witmore discovered that the play's uncanniness results from the recurrent usage of the definite article the (2014). The two scholars thus performed a word-frequency analysis - namely, the log-likelihood of words in the menacing play. "So they compared word-usage in Macbeth to Shakespeare's overall writing. What words did he use in Macbeth more frequently than in his other plays?" (Thompson, 2021).

\begin{tabular}{|c|c|c|c|c|c|c|c|}
\hline Lemma & $\begin{array}{l}\text { Word } \\
\text { class }\end{array}$ & $\begin{array}{l}\text { Relative } \\
\text { use }\end{array}$ & $\begin{array}{l}\text { Log } \\
\text { likelihood }\end{array}$ & $\begin{array}{l}\text { Analysis } \\
\text { parts } \\
\text { per } \\
10,000\end{array}$ & $\begin{array}{l}\text { Reference parts } \\
\text { per } 10,000\end{array}$ & $\begin{array}{l}\text { Analysis } \\
\text { count }\end{array}$ & $\begin{array}{l}\text { Reference } \\
\text { count }\end{array}$ \\
\hline thane & $n$ & + & $156.1^{* * * *}$ & 18 & 0.35 & 30 & 30 \\
\hline hail & $\mathrm{v}$ & + & $51^{* * * *}$ & 10 & 0.82 & 17 & 71 \\
\hline knock & $v$ & + & $49.8^{* * * *}$ & 11 & 1.17 & 19 & 101 \\
\hline cauldron & $\mathrm{n}$ & + & $41.6^{* * * *}$ & 4.8 & 0.09 & 8 & 8 \\
\hline our & po & + & $41.5^{* * * *}$ & 71 & 36.76 & 119 & 3180 \\
\hline she & pn & - & $41.3^{* * * *}$ & 21 & 53.05 & 35 & 4590 \\
\hline the & dt & + & $41^{* * * * *}$ & 422 & 327.07 & 703 & 28298 \\
\hline tyrant & $\mathrm{n}$ & + & $40.2^{* * * *}$ & 9 & 0.89 & 15 & 77 \\
\hline sleep & $n$ & + & $33.3^{* * * *}$ & 9.6 & 1.38 & 16 & 119 \\
\hline weird & j & + & $31.2^{* * * *}$ & 3.6 & 0.07 & 6 & 6 \\
\hline i & pn & - & $28.6 * * * *$ & 283 & 359.55 & 472 & 31108 \\
\hline trouble & $\mathrm{n}$ & + & $27.3^{* * * *}$ & 5 & 0.43 & 9 & 37 \\
\hline dagger & $\mathrm{n}$ & + & $26.3^{* * *}$ & 6 & 0.61 & 10 & 53 \\
\hline wood & n 1 & + & $25.9^{* * *}$ & 6.6 & 0.8 & 11 & 69 \\
\hline fear & $\mathrm{n}$ & + & $24.5^{* * *}$ & 13.8 & 3.88 & 23 & 336 \\
\hline
\end{tabular}

Figure 3: Macbeth - Word-frequency analysis (Hope \& Witmore, 2014)

While spooky words such as cauldron, dagger, fear or horror were expected to be prevalent in an eldritch play such as this, it is the overuse of the article the, often instead of 
indefinite articles $a$-an, or the possessive adjective $m y$, that creates the spooky feeling when reading or watching the play. The solving of this enduring enigma was possible with the help of computers and advanced statistics (Thompson, 2021): "It was the owl that shriek'd, the fatal bellman,/Which gives the stern'st good-night (Shakespeare, 1997, p. 1)"; "Let not light see my black and deep desires;/the eye wink at the hand; yet let that be,/Which the eye fears, when it is done, to see" (Shakespeare, 1997, p. 50). Thus, by "using data analysis to ponder literature", the two scholars have managed to decode a mystery that Macbeth's readers of all times have been confronted with. While the play can in no way be regarded as a mere pile of words that can only be understood by computation, the new scientific methods of analysing it can help both critics and readers to find the open secret that renders it unsettlingly memorable, although the Shakespearean play, "like all good art [...] can't be reduced to any single literary effect" (Thomson, 2021).

Being Human in conversation is a "series of free, online and year-round events launched in 2020, produced by the Being Human festival." All the guests of the series have explored the practicality of the humanities and their direct relation to real life. Among the topics of debate in 2020 was "the benefits of a more diverse, inclusive reading diet" for the sole reason of living "in a time demanding changes to the way in which society is run", changes that also affect the books read and taught in schools and "generally agreed to be good, important and worth studying" (Being Human, 2020). Sarah Churchwell is professor of American Literature and Public Understanding of the Humanities at the University of London (Guardian, n.d.). Karina van Dalen-Oskam is Head of the Department of Literary Studies of Huygens Institute for the History of the Netherlands and Professor of Computational Literary Studies at the University of Amsterdam (eadh, n.d.). At Being Human festival 2020, the two distinguished professors virtually met the Irish writer Kit de Waal and they all debated on expanding, conserving and putting the English literature canon under revision as they introduced two scientific projects that aimed to understand individual and collective reading habits and how literature impacts one's vision of the world. Professor van Dalen-Oskam thus gave a short talk on the University of Wolverhampton's AHRC-funded project Novel Perceptions: Towards an Inclusive Canon (NOPE), then invited the audience to rate the covers of the books on the BBC's Novels That Shaped Our World list in order to see whether covers influence personal and unified perceptions of literary quality (de Waal, 2020). The research project NOPE, which received $£ 300,000$ from the Arts and Humanities Research Council (AHRC), aims to investigate readers' opinions about the literary quality of contemporary fiction. Sebastian Groes, Professor of English Literature in the School of Humanities at the University of Wolverhampton and Karina van Dalen-Oskam have been leading a team of computational linguistics and English literature scholars to analyse readers' response to one hundred emblematic novels since Robinson Crusoe. The academic team will be analysing, both quantitatively and qualitatively, readers' book preferences and opinions about literary quality while assisting the BBC, Libraries and Reading Groups in establishing the public's degree of engagement with the monthly group of ten novels from the ten categories of a joint project called The Novels That Shaped Our World: (1) Identity; (2) Love Sex and Romance; (3) Adventure; (4) Life, Death and Other Worlds; (5) Politics, Power and Protest; (6) Class and Society; (7) Coming of Age; (8) Family and Friendship; (9) Crime and Conflict; (10) Rule Breakers. The genre-busting novels in the selected categories have also influenced the panel - that is, the journalist and broadcaster Mariella Frostrup, the bestselling author, screenwriter and columnist Juno Dawson, the writer Kit de Waal, the journalist, BBC Radio 4 Front Row presenter and editor of The Times Literary Supplement, Stig Abell, and the author Alexander McCall Smith. While regular data analysis will indicate the public's literary preferences and judgment, at the end of the interdisciplinary research, an overview of the whole experience will be provided by means of a longer survey (NOPE, n.d.).

Similarly, in the 2020 Reader Review research, which is also part of Professor Karina van Dalen-Oskam's interdisciplinary work, readers are being asked to assign literary quality to contemporary novels (nQuire, n.d.). Another interdisciplinary research, Novel Memories, aims 
at revealing (1) the public's memory of the stories read in the past; (2) how mood shapes the understanding of stories; (3) how certain personal emotions could be associated with certain characters and books; (4) what novels influence readers' life, and why; (5) how rereading these novels could change original opinions of them. In the same vein, The Riddle of Literary Quality project (2012-2019) aimed to understand how cognitive biases could underlie the public's reading patterns, publishing industry and school curricula. Thus, the main objectives of the latter project were (1) to see whether all forms of stylistic devices in contemporary novels could be measured; (2) to establish the literary, Nobel-Prize winning features of novels; (3) to decide the influence of direct speech on readers' literary perceptions; (4) to determine how important clichés and complex sentences are in the novelistic fabric. All these projects can already prove that computers and literature can work together and that literary quality could be partly measured (NOPE, n.d.).

Another example of interdisciplinarity for the benefit of literary theory and literature is the Stanford Literary Lab, "a research collective that applies computational criticism, in all its forms, to the study of literature. [...] The Lab is open to students and faculty at Stanford, and [...] to those from other institutions. [...] At the Lab, all research is collaborative [...]" (Literary Lab, 2010, para.1). The Lab's projects are mainly based on computer-generated images, graphs and maps. One project, for instance, is called Fanfiction: Generic Genesis and Evolution and analyses two decades of fanfiction using advanced software. Its goal is "to study the development and progression of genre [...] in order to track both authorial and readerly influence, the development of generic innovation, and the genesis and evolution of specific archetypes and stylistic conventions". This interdisciplinary activity also has a multilingual sub-project that analyses fan fiction "as a global phenomenon. [...] This sub-project compares three facets of metadata across an English, Italian, and Russian fanfic archive: the conceptualization of "genre", the material that necessitates a "warning", and how characters are romantically paired". Another project, called Microgenres, uses computers to identify the interdisciplinary nature of novelistic discourses - namely, the incorporation of linguistic and stylistic elements from contemporary disciplines such as history, philosophy or natural science (Literary Lab, 2010, para 3). The complexity of novels is thus proved both synchronically and diachronically and in relation to the term "heteroglossia", which signifies two interrelated meanings within the same "linguistic code" (Bakhtin, 1981, p. 33). The Project Reading Norton Anthologies: Canons and Trajectories "examines every text included in every edition of the various Norton series since M.H. Abrams edited the first Norton Anthology of English Literature in 1964" in order to determine the role that the Norton played in creating a literary canon and the dynamics of this canon. The interdisciplinary project Suspense: Language, Narrative, Affect entails a linguistic, narrative and psychological analysis "of 'suspenseful' texts from 1750 to the present day" in order to determine whether suspense is either a collective or an individual manifestation, or both, in accordance with the temporal and spatial changes of each period (Literary Lab, 2010). A computer-based project that "aims to reconstruct racial discourse in American literature" is Representations of Race and Ethnicity in American Fiction, 1789-1964 while the Trans-Historical Poetry Project analyses "the variation of poetic form over a large corpus of English-language poetry, combining the insights of prosodic and metrical analysis with the methods of phonetics, natural language processing, and statistics". Similarly, the Translation Project "looks at the ways that English translations of foreign-language texts literature diverge from original English literature at the morpho-syntactic level and examines both the sources and the impact of those divergences" while the Typicality Project focuses on atypical novels and how literary critics interpret novelistic originality that still falls under certain genres. Yet another collaborative project, "Literature/Littérature": History of A Word, studies "the history of the concept of literature" by means of "broad lexicographical research" and "solid quantitative evidence from both the French and the English tradition" (Literary Lab, 2010).

The scientific approach to literature thus facilitates the analysis of large corpora of literary texts, which include "The Great Unread" as well as the canonical works, in order to 
provide larger bird-eye-views and certain statistical patterns of the traditional and innovative instruments of creative writing and literary criticism (Cohen, 2009, pp. 51-75). Furthermore, when famous universities such as Stanford create the opportunity for students to study computer science together with music or English, it is hard not to notice the interdisciplinary future of all research and teaching (Rothman, 2014). Referring to world literature as "a planetary system", hardly covered by comparative studies, which mainly deal with the canonical fractions, Franco Moretti wonders how the significant remainder of literary texts should be properly studied. His answer is "distant reading", which mainly means providing quotations that prove one's critical research instead of close reading - that is, personal analysis and synthesis of canonical works, which are hardly representative of world literature as a system that is "one and unequal": "[...] reality is infinitely rich; concepts are abstract, are poor. But it's precisely this 'poverty' that makes it possible to handle them, and therefore to know. This is why less is actually more" (Moretti, 2000, p. 58). By creating, for instance, a vast bibliography of 7,000 British novel titles between 1740 and 1850 in accordance with the length of titles and the publication density, the interdisciplinary researcher discovers that novel titles shorten over time while the marketing power increases (Moretti, 2009, p. 141). The pace of forgetting history is demonstrated by another vast study on distant reading, which consists in plotting the number of words and the frequency of individual words in books with regard to the highs and lows of certain years (Michel, et al., 2011, p. 179). Also, by providing diachronic $\mathrm{x}-\mathrm{y}$ axes that indicate the extinction and emergence of literary genres, Moretti wants to prove the futility of interpreting the same canonical texts over and over again. He thus suggests that literary critics should focus "on explanation, rather than interpretation" in order to produce realistic insights into the language of world literature, because theories "will never abolish inequality: they can only hope to explain it (Moretti, 2003, pp. 73-81). This may come against de Man's deconstructionist way of reading literature as an instable relation between "the literal and the figurative, between grammatical and rhetorical modes of meaning": "The deconstruction is not something we have added to the text but it constituted the text in the first place. A literary text simultaneously asserts and denies the authority of its own rhetorical mode and by reading the text as we did, we were only trying to come closer to being as rigorous a reader as the author had to be in order to write the sentence in the first place" (de Man, 1973, p. 31). Literature scholars such as Moretti therefore propose the counting, graphing and mapping of novels instead of reading them in order to renew and systematise literary studies and historiography. By having focused on the close reading of a few hundred books, critics have created a false image of the literary system. Through distant reading that consists of bar charts, maps and time lines, an accurate historiographical perception of genres could be obtained along with the radical redefinition of aesthetic forms (Moretti, 2005, p. 43).

\section{Study Overview}

The English writer of Japanese origins Kazuo Ishiguro mainly writes about the exhausting search for meaning through introspection and recollection of troubled pasts, in accordance with Vonnegut's category of Hamletian life stories and Whyte's manifesto of true love: "We are so seldom told the truth. In Hamlet, Shakespeare tells us we don't know enough about life to know what the good news is and what the bad news is, and we respond to that" (Johnson, 2019, para. $10)$; “[...] if you wanted to drown you could, but you don't because finally after all this struggle and all these years you simply don't want to any more, you've simply had enough of drowning and you want to live and you want to love" (Johnson, 2016, p. 7). The integrated vision of the history of ideas could thus be considered the cultural basis for the psycho-literary approach to Kazuo Ishiguro's novels. The environment plays a major role in shaping the literary process as well as the lives of Ishigurian characters, be they heroes or anti-heroes. Ishiguro's mission is therefore to assist the reader in getting access to lost or reconfigured values within his or her inner world, hence the need for a holistic understanding of Ishiguro's novels (Wong, 2005, pp. 5-7).

Analysing Ishiguro's novels from an integrative perspective can thus bring multiple 
dimensions of understanding, so a scientific approach can only enhance the results obtained through analytical and synthetical observation. The current paper reports briefly on a vast study called Distorted Temporality in Kazuo Ishiguro's Novels: A Holistic Approach, which analysed the distorted nature of time in Ishigurian characters' perception, integrating concepts of literary and cultural criticism with neurolinguistics, philosophy, psychology, spirituality, social cognition, phenomenology, anatomy, neuroscience, behavioural economics, game theory, mathematics, theoretical physics and quantum mechanics. In the first part of "Literature Review", the concept of impaired time perception was analysed in connection with the themes, symbols, motifs, concepts and theories specific to each novel; the second part offered interdisciplinary overviews of the main Ishigurian themes and techniques as well as syntheses of the novels in accordance with these literary and linguistic devices, thereby proving that the concept of distorted temporality bonds all the other themes together: time, memory, identity, displacement, historiography, trauma, post-traumatic stress disorder, behaviour and linguistic modelling. The empirical purpose of the study thereof consisted in investigating the correlation between Kazuo Ishiguro's novels and the temporal perception of Romanian and foreign readers, by analysing both the influence of Kazuo Ishiguro's novels on readers' perception of time and the influence of readers' perception of time on their interpretation of Kazuo Ishiguro's novels.

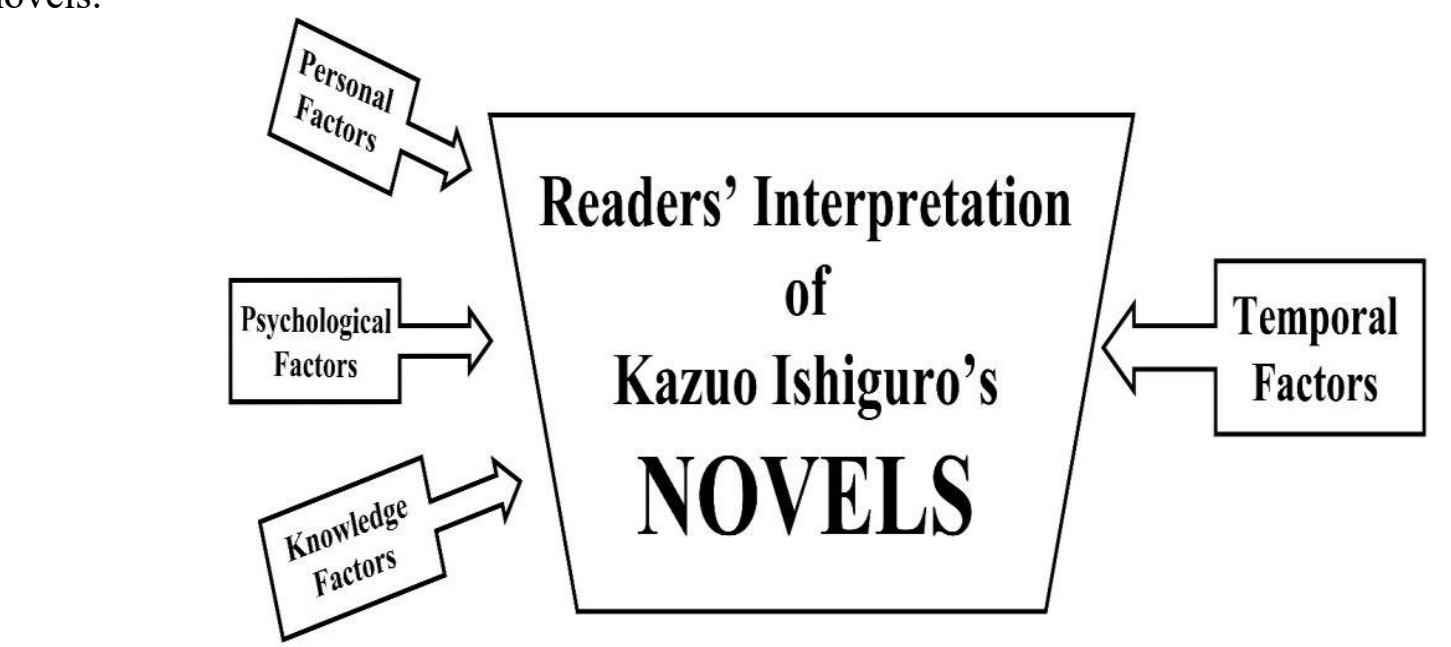

Figure 4: Kazuo Ishiguro study - Hypothesis 1

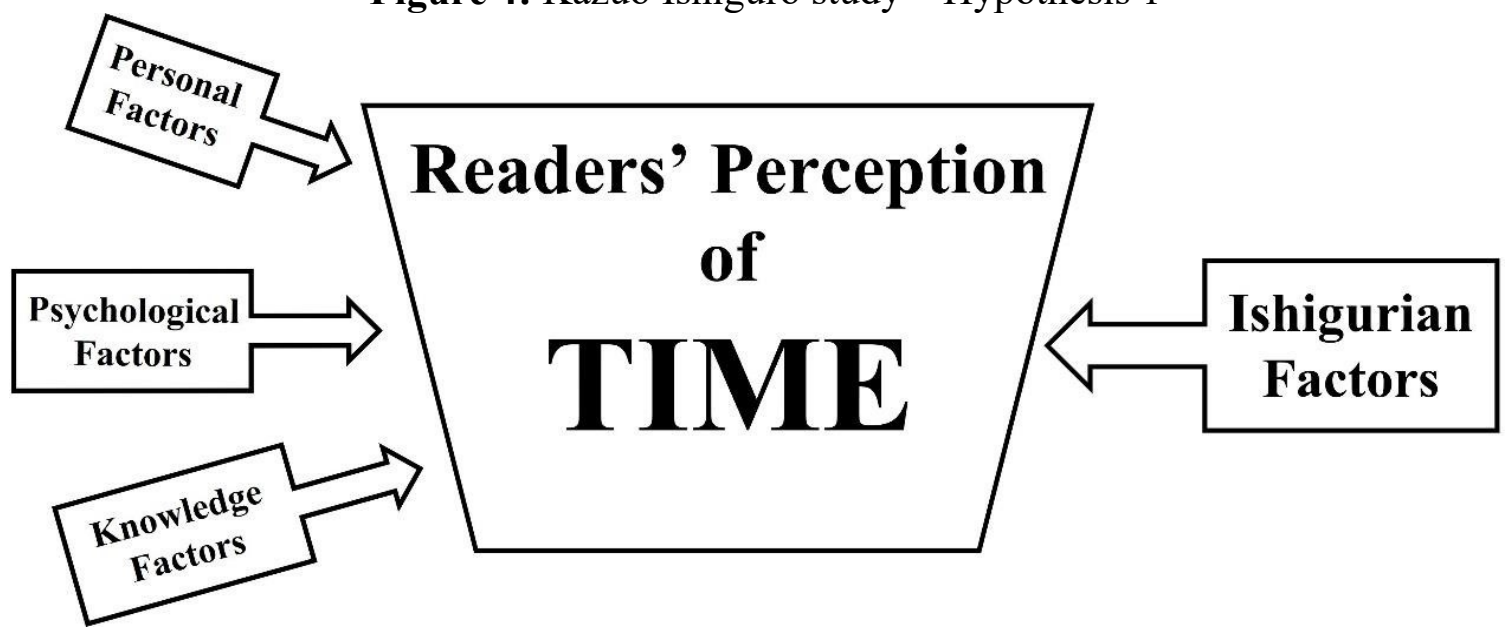

Figure 5: Kazuo Ishiguro study - Hypothesis 2

The study used both primary and secondary data (Saunders, et al., 2009, pp. 256-288). Primary data was collected from first-hand sources, using the method of surveying. Secondary data - that is, the main sources for the integrative interpretation of Kazuo Ishiguro's novels comprised academic journals, articles, periodicals, books and prior studies relevant to the variables in the current analysis. The interdisciplinary study used a quantitative approach, through one self-administered questionnaire with closed- and open-ended questions in English, to collect 
the primary data for testing the hypotheses, answering the research questions, and meeting the research objectives. The validated survey Metacognitive Questionnaire on Time: Feeling of the Passage of Time was used for questionnaire validation (Lamotte, et al., 2014). Some of the questionnaire's items and questions were also created based on secondary data - that is, studies and books containing information directly related to the segments to be measured. The questionnaire was administered to both Romanian and foreign respondents and contained 29 scales, with different numbers of items that measured different dimensions corresponding to the classes of factors in the study. The questionnaire was thus divided into five parts, each being subdivided according to the dimensions belonging to each factorial class:

- Part 1 (Questions 1-7): Items about personal factors

- Part 2 (Question 8): Item about psychological factors

- Part 3 (Questions 9-11): Items about knowledge factors

- Part 4 (Questions 12-18): Items about temporal factors

- Part 5 (Questions 19-29): Items about Ishigurian factors

Closed-ended and open-ended questions were used in the current study as follows:

- factual questions: demographical data

- behavioural questions: data about respondents' choices and decisions

- opinion questions: data about respondents' viewpoints

- attitude questions: data about respondents' beliefs and perspectives

- motive questions: data about respondents' drives and motivators

- knowledge questions: literary information

The measures used in the questionnaire are nominal, ordinal and interval scales. Based on the above classification, the closed-ended and open-ended questions in the current study can be classified as follows (Saunders, et al., 2009, 360-414):

- single-answer multiple choice questions (mutually exclusive categories)

- Yes-No questions

- questions with short answers

- 7-point Likert Scale measuring frequency of variables

- 7-point Likert Scale measuring respondents' agreement with variables

- 7-point Semantic Differential Scale measuring respondents' satisfaction with variables

- 7-point Semantic Differential Scale measuring likelihood of variables

- 7-point Semantic Differential Scale measuring respondents' interest in variables

- 7-point Semantic Differential Scale measuring pleasantness of variables

- 7-point Semantic Differential Scale measuring importance of variables

- 7-point Semantic Differential Scale measuring confidence in variables

\begin{tabular}{|l|c|c|}
\hline No. & Classes of independent variables & Sub-classes of independent variables \\
\hline 1 & Personal variables & \\
& & Demographics \\
& & Age \\
& & Place of residence \\
& & Marital status \\
& & $>$ Education system \\
\hline 2 & Psychological variables & $>$ Personality condition status \\
\hline 3 & Knowledge variables & $>$ Reading experience \\
& & $>$ English level \\
\hline
\end{tabular}

Table 1: Kazuo Ishiguro study - Variables 1 
Thus, there were four classes of independent variables or influential factors relating thereto: (1) personal factors; (2) psychological factors; (3) knowledge factors; (4) temporal factors or Ishigurian factors.

The dependent variable of the current study was therefore either Reader's perception of time or Readers' interpretation of Kazuo Ishiguro's novels. The former consisted of 7 scales with 1, 1, 1, 20, 4, 18, 17 items, respectively; the latter consisted of 11 scales with 7, 6, 12, 11, $8,6,14,7,1,1,1$ items, respectively.

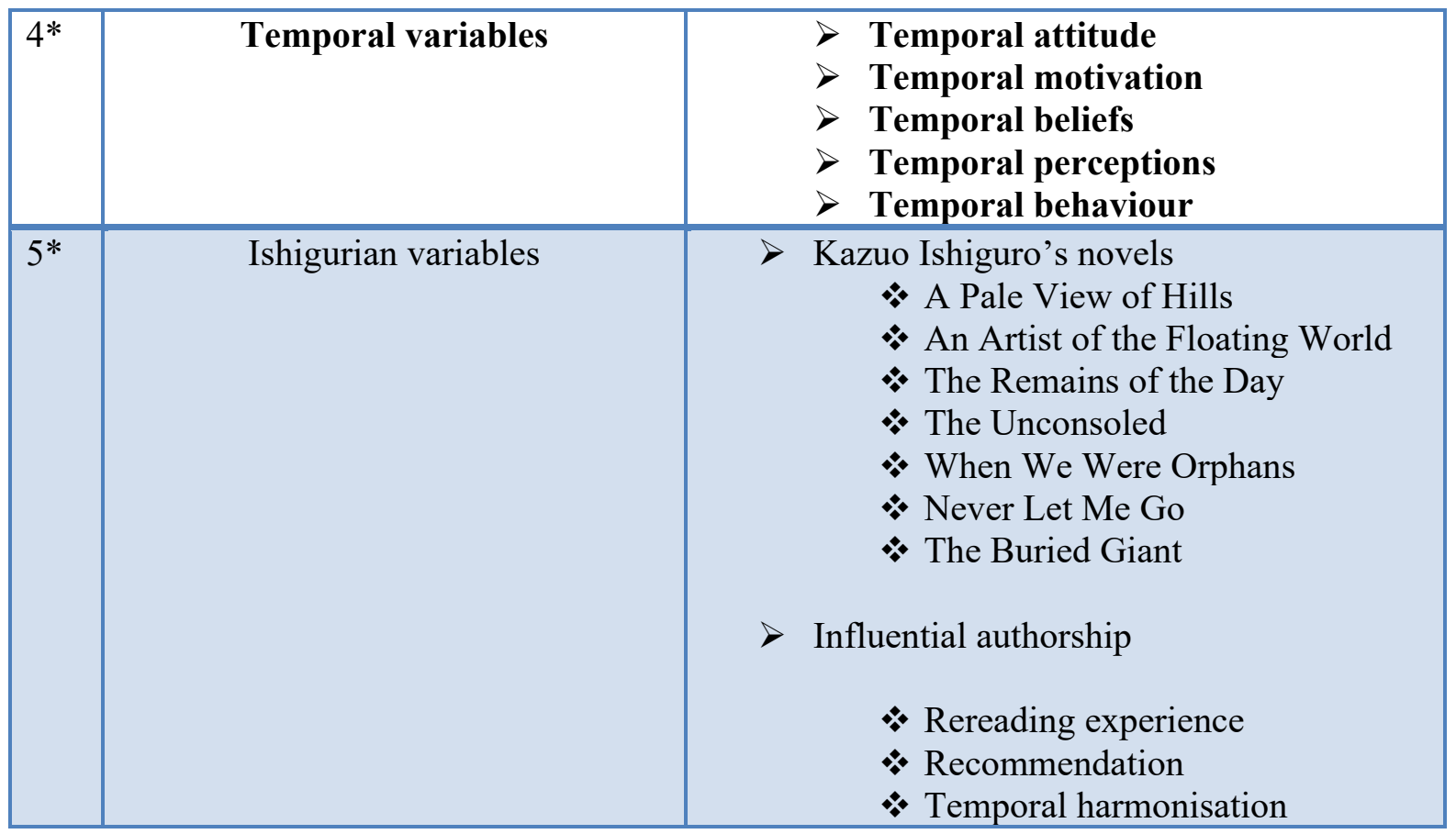

Table 2: Kazuo Ishiguro study - Variables 2

The logic behind the two dependent variables in the two different research scenarios was to provide more accurate results regarding the correlation between Kazuo Ishiguro's novels and readers' perception of time. The survey was completed by 2610 Romanian and foreign readers, from high school students aged 15 to senior citizens. Special care was taken of how the questions were worded as well as how the questionnaire was formatted in order to avoid selection and information biases and measurement error (Saunders, et al., 2009, pp. 360-414). Data collection was conducted by using non-probability sampling technique, which means that the samples were gathered without giving all the readers equal chances of being selected. The two types of non-probability sampling techniques used for collecting the data were convenience sampling and snowball sampling, meaning, respectively, that the subjects were selected because of their convenient accessibility and proximity to the researcher and by asking the main subjects to recruit other readers (Taherdoost, 2016, pp. 18-27).

The collected data was analysed with the help of two statistical programs: RStudio 4.3.4. and Warp PLS 6.0. The study used descriptive statistics (frequency, percentages) to explain the demographics and readers' answers to the factorial classes in the questionnaire. Inferential statistics, based on confidence intervals and hypothesis testing, was also employed, the main statistical tools used in the current study being multiple linear regression, binomial logistic regression, one-way ANOVA, structural equation modelling (SEM), as well as tests of significance such as t-tests. Partial least squares structural equation modelling (PLS-SEM), also called Partial least squares path modelling (PLS-PM), was used in the first part of data analysis to determine the relationships between the observed data and the latent variables as well as the relationships between the latent variables. Data analysis was divided into three separate sets of results for each statistical instrument used to measure the influential degree of each factorial 
class: (1) descriptive statistics; (2) inferential statistics 1; (2) inferential statistics 2; (4) path analysis. For humanistic purposes, most of the statistical calculations were left out so that the study presented only a conceptualised version of the statistical results.

\section{Results and Discussion}

The findings indicate that readers' perception of time is influenced by personal, psychological, knowledge and Ishigurian factors while their interpretation of Kazuo Ishiguro's novels is influenced by personal, psychological, knowledge and temporal factors, so there is a strong correlation between Kazuo Ishiguro's novels and the temporal perception of Romanian and foreign readers. The results also offer interesting perspectives on how the classes of factors and their dimensions influence each other, both as a whole and in specific demographic and behavioural circumstances, in relation to readers' perception of time and their interpretation of Kazuo Ishiguro's novels.

Thus, a very brief statistical summary of readers' perception of time indicates that most readers have a positive attitude towards life, keeping their hopes high while trying to learn from their past mistakes and live their present to the full. Also, most readers interpret their past events based on their present emotional states while experiencing the same perceptual distortions of time dilation and contraction as the ones psychologically acknowledged by specialists. As regards readers' interpretation of Kazuo Ishiguro's novels, a very brief statistical summary indicates that the most appreciated books are Never Let Me Go, The Remains of the Day and The Buried Giant; the least appreciated book is The Unconsoled; and the least read book is When We Were Orphans, followed by The Unconsoled. Most respondents waver between the degrees of liking Ishiguro's works, which proves the novels' intriguing and highly interactive nature. Even when they feel less impressed by Ishiguro's books, most readers seem unable to stop thinking about the novels' intriguing contents. Readers' willingness to reread and recommend Ishiguro's novels, even when they do not feel particularly attached to them, proves the novels' haunting nature as well as their interactive character. The willingness of most readers to further adjust their temporality in accordance with the existential lessons Ishiguro teaches his readership proves the strong correlation between his novels and readers' perception of time: On the one hand, readers' own perception of time renders Ishiguro's novels attractive for his sincere perspectives on the human condition, with its distorted temporality and unreliability of recollection; on the other hand, Ishiguro's novels can influence readers' temporality, enhancing its natural, life-preserving distortion while redressing readers' temporal misconceptions and misbeliefs. Thus, after they have read Kazuo Ishiguro's novels, readers are willing to change or enhance their perception of time for the betterment of their own lives. The primary purpose of the second category of hypothesis testing was to outline some important aspects in Romanian and foreign readers' perception and interpretation that may further emphasise the correlation between Kazuo Ishiguro's novels and readers' perception of time. As such, a series of items were extracted from the scales and sub-scales constituting the factorial dimensions in order to be treated as independent and dependent variables. Testing the new hypotheses sealed the accuracy of the results in the SEM analysis while further testing the five main hypotheses and adding new layers of understanding readers' temporality in conjunction with Kazuo Ishiguro's novels.

\section{Conclusion}

Whether or not this fusion is fully acknowledged, the fields of study and research have always influenced and interacted with each other. Therefore, instead of a non-professional invasion of the research spaces of other specialists, a viable solution to the problem of specialisation consists in the cooperation of all fields in order to establish healthy channels of communication and mutual assistance. Only in this way will the fruitful correlation between practice and theory also consecrate the healthy individuality of all studies and disciplines involved.

As the results of the case study indicate, Ishiguro's individual and collective examples of 
temporal impairment can help readers restore their own temporality to its healthy distortion. Future research should therefore focus more on the fusion of fields, using literature for therapeutic and behavioural purposes, reducing all confusing terminology and further identifying and explaining the multitude of factors that influence people's perceptions, beliefs, choices and decisions. This may prove that the concept of invisible hand can prevail among the specialists that are willing to cooperate in order to create a truly harmonious world (Smith, 2009, p. 456). However, for all the accuracy of the statistical results of the study, life largely remains an unmeasurable variable, simply because the scientific field lacks the proper instruments to prove the existence of consciousness. Future research should thus also focus on teaching humans how to trust implicitly the scientific results brought by the most accomplished technology on the planet up to date: the human being in its physical, mental, emotional and spiritual greatness. Although there will always be many mysteries in the microcosm and the macrocosm perceived by the human mind, mankind should not deny itself the miracle of authentic living, hence the obvious direction towards interdisciplinarity of all research, including cultural studies, new critical paradigms and the humanities.

Conducting quantitative research on literature begets the necessity of repetition. "Explanatory models are derived from observable trends, and those models are continuously tested against further evidence until the model most accurately reflects reality" (Reid, 2019, p. 5). However, while many innovative ways can be found to test literary hypotheses by virtue of modern technology, regularly applying scientific methods of research to literature can still pose an interdisciplinary challenge. Given the nature of literary data, the new specialisation of digital humanities, consisting of cultural analytics, literary data and text mining, quantitative formalism, computational criticism and textual analysis, algorithmic, computational and social computing for literary studies, may still be regarded as a counter-productive way of analysing good art as opposed to the traditional way of studying and valuing literary books (Merrill, 2018; Ascari, 2014, pp. 1-16); Da, 2019, p. 601). Yet, in time, statistical inquiry could successfully serve literature as its highly technologized instruments gradually establish new directions of rereading and analysing in order to find "the laws of literary history" (Rothman, 2014) as well as an accurate image of global literature.

\section{References}

Ascari M. (2014). The Dangers of Distant Reading: Reassessing Moretti's Approach to Literary Genres. Genre 47(1), DOI 10.1215/00166928-2392348

Bakhtin, M. M. (1981). The Dialogic Imagination. In Holquist M. (Ed.) and Emerson C. and Holquist M (Trans.), Four Essays by M.M. Bakhtin, Austin and London: University of Texas Press.

Being Human. (2020). Being Human in Conversation. Being Human: A Festival of the Humanities. https://beinghumanfestival.org/in-conversation.

Beinhocker, E. D. (2006). The Origin of Wealth: The Radical Remaking of Economics and What It Means for Business and Society. Boston, Massachusetts: Harvard Business School Press.

Churchwell, S. Profile. The Guardian. https://www.theguardian.com/profile/sarahchurchwell. Cohen, M. (2009). Narratology in the Archive of Literature. Representations 108(1), 51-75.

Dalen-Oskam, K. van. Profile. European Association for Digital Humanities. https://eadh.org/karina-van-dalen-oskam

Da, N. Z. (2019). The Computational Case against Computational Literary Studies. Critical Inquiry 45(3), 601-639, DOI: 10.1086/702594

Gallo, C. (2014). Talk like TED: The 9 Public Speaking Secrets of the World's Top Minds. Pan Macmillan.

Hanschell, W. (2021, December 3). The Shapes of Stories \& AI. pencil. https://www.trypencil.com/post/the-shapes-of-stories-ai 
Hill, N. (2005). Think and Grow Rich. TarcherPerigee.

Huygens. The Riddle of Literary Quality. https://www.huygens.knaw.nl/projecten/the-riddleof-literary-quality/

Jackson, F. (1982). Epiphenomenal Qualia. Philosophical Quarterly 32(127), 127-136, DOI:10.2307/2960077. JSTOR 2960077

Jackson, F. (1986). What Mary Didn't Know. Journal of Philosophy 83(5), 291-295, DOI:10.2307/2026143. JSTOR 2026143

Johnson, S. (2019, December 27). Kurt Vonnegut on 8 shapes of stories. Big Think, https://www.bigthink.com/culture-religion/vonnegut-shapes?rebelltitem=3

Hope, J. \& Witmore, M. (2014). The Language of Macbeth. In Thompson, A. (Ed.), Macbeth: The State of Play, London: Bloomsbury (Arden), 183-208.

Jung, C. G. (2012). Man and His Symbols. Random House Publishing Group.

Lafrance, A. (2016, July 12). The Six Main Arcs in Storytelling, as Identified by an A.I. The Atlantic. https://www.theatlantic.com/technology/archive/2016/07/the-six-main-arcsin-storytelling-identified-by-a-computer/490733/

Lamotte, et al. (2014). Metacognitive Questionnaire on Time: Feeling of the Passage of Time. Timing \& Time Perception 2(3), 339-359, DOI: 10.1163/22134468-00002031

Literary Lab. (2010). Stanford Literary Lab: Projects. https://litlab.stanford.edu/projects/

Lovejoy, A. O. (1940). Reflections on the History of Ideas. Journal of the History of Ideas $1(1), 3-23$.

Man, P. de (1973). Semiology and Rhetoric. Diacritics 3(3), Johns Hopkins University Press, 27 33, https://doi.org/10.2307/464524

Menand, L. (2014, March 17). The de Man Case: Does A Critic's Past Explain His Criticism? The New Yorker. A Critic at Large, 24 March 2014 Issue. https://www.newyorker.com/magazine/2014/03/24/the-de-man-case

Merrill, J. (2018, May 2). Distant Reading in Russia: Franco Moretti and the Formalist Tradition. Eurozine. https://www.eurozine.com/distant-reading-russia-franco-morettiformalist-tradition/

Michel, J.-B., et al. (2011). Quantitative Analysis of Culture Using Millions of Digitized Books. Science 331(6014), 179.

Moretti, F. (2000). Conjectures on World Literature. New Left Review 1, 54-68. https://newleftreview.org/issues/ii1/articles/franco-moretti-conjectures-on-worldliterature

Moretti, F. (2003). More Conjectures on World Literature. New Left Review 20, 73-81. https://newleftreview.org/issues/ii20/articles/franco-moretti-more-conjectures

Moretti, F. (2005). Graphs, Maps, Trees: Abstract Models for a Literary History. London: Verso.

Moretti, F. (2009). Style, Inc. Reflections on Seven Thousand Titles (British Novels, 17401850). Critical Inquiry 36 (1), 141.

Nietzsche, F. (2006). On Truth and Lies in a Nonmoral Sense. The Nietzsche Reader, Pearson, K. A. \& Large, D. (Eds.). Malden, MA: Blackwell.

Novel Perceptions. (2020). The Novels That Shaped Our World. NOPE. http://novelperceptions.thememorynetwork.com/

nQuire. (2020). The 2020 Reader Review. nQuire: Explore your World. https://nquire.org.uk/mission/the-2020-reader-review/contribute

Osho. (2012). The Goose Is Out: Zen in Action. New York: Osho Media International.

Reid D. (2019). Distant Reading, 'The Great Unread', and $19^{\text {th }}$ Century British Conceptualizations of the Civilizing: A Case Study. Journal of Interdisciplinary History of Ideas 15, Varia. http://journals.openedition.org/jihi/435

Rothman, J. (2014, March 20). An Attempt to Discover the Laws of Literature. The New Yorker. https://www.newyorker.com/books/page-turner/an-attempt-to-discover-thelaws-of-literature

Saunders, M., et al. (2009). Research Methods for Business Students. Pearson Education. 
Shakespeare, W. (1997). Macbeth. Wordsworth Editions Ltd.

Smith, A. (2009). An Inquiry into the Nature and Causes of the Wealth of Nations. Thrifty Books.

Taherdoost, H. (2016). Sampling Methods in Research Methodology: How to Choose a Sampling Technique for Research. International Journal of Academic Research in Management 5(2), 18-27.

Thompson, C. (2021, August 11). How Data Science Pinpointed the Creepiest Word in Macbeth. OneZero. https://onezero.medium.com/how-data-science-pinpointed-thecreepiest-word-in-macbeth-3150995d 3808

Thompson, V. A., et al. (2011). Intuition, Reason and Metacognition. Elsevier 63(3), $107-$ 140.

Vonnegut, K. [Eva CollinsAlonso]. (2004, February 4). Shape of Stories [Video]. Youtube. www.youtube.com/watch?v=GOGru_4z1 Vc

Waal, K. de. [Being Human Festival]. (2020, November 16). Novels That Shaped My World [Video]. Youtube. https://www.youtube.com/watch?v=BINEGEcpsnE

Whyte, D. (2016). The Sea in You: Twenty Poems of Requited and Unrequited Love. Many Rivers Press.

Wong, C. F. (2005). Kazuo Ishiguro. Tavistock: Northcote House.

\section{Bio-note}

Dr. Amalia Călinescu is a postgraduate holistic researcher, with a $\mathrm{PhD}$ in Philology and two Master's degrees, in Literary Translation and Behavioural Economics, from the University of Bucharest, Romania. She is the author of several articles and books, which can be found through my website, in international journals, on Amazon, or in bookstores worldwide. She is deeply interested in the therapeutic role of literature with regard to human interconnection and the decision-making process, hence her preoccupation with interdisciplinary research. In the near future, she will occupy a lecturing position at the University of Bucharest and publish many other books and interdisciplinary studies.

ORCID ID: https://orcid.org/0000-0002-7360-8418

Website: www.holistic-english.com

Email: amalia.calinescu@drd.unibuc.ro 